\title{
Analgesic and anti-inflammatory potential of Lupeol isolated from Indian traditional medicinal plant Crateva adansonii screened through in vivo and in silico approaches
}

Thirumalaisamy Rathinavel ${ }^{1 *}$, Subramanian Ammashi ${ }^{2}$ and Gnanendra Shanmugam ${ }^{3}$

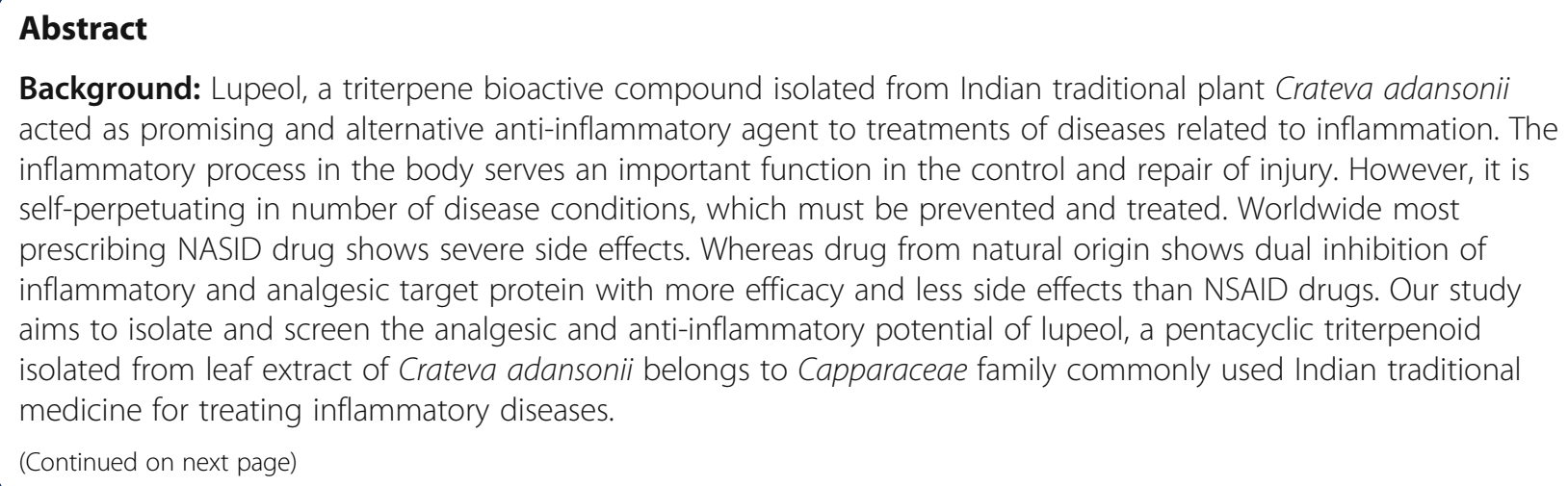

Background: Lupeol, a triterpene bioactive compound isolated from Indian traditional plant Crateva adansonii acted as promising and alternative anti-inflammatory agent to treatments of diseases related to inflammation. The inflammatory process in the body serves an important function in the control and repair of injury. However, it is self-perpetuating in number of disease conditions, which must be prevented and treated. Worldwide most prescribing NASID drug shows severe side effects. Whereas drug from natural origin shows dual inhibition of inflammatory and analgesic target protein with more efficacy and less side effects than NSAID drugs. Our study aims to isolate and screen the analgesic and anti-inflammatory potential of lupeol, a pentacyclic triterpenoid isolated from leaf extract of Crateva adansonii belongs to Capparaceae family commonly used Indian traditional medicine for treating inflammatory diseases.

(Continued on next page)

\footnotetext{
*Correspondence: tmalaisamy@gmail.com

'Department of Biotechnology, Sona College of Arts and Science, Salem,

Tamil Nadu 636 005, India

Full list of author information is available at the end of the article
}

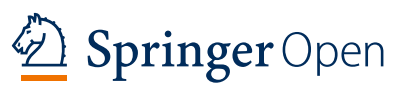

(c) The Author(s). 2021 Open Access This article is licensed under a Creative Commons Attribution 4.0 International License, which permits use, sharing, adaptation, distribution and reproduction in any medium or format, as long as you give appropriate credit to the original author(s) and the source, provide a link to the Creative Commons licence, and indicate if changes were made. The images or other third party material in this article are included in the article's Creative Commons licence, unless indicated otherwise in a credit line to the material. If material is not included in the article's Creative Commons licence and your intended use is not permitted by statutory regulation or exceeds the permitted use, you will need to obtain permission directly from the copyright holder. To view a copy of this licence, visit http://creativecommons.org/licenses/by/4.0/. 
(Continued from previous page)

Results: Methanol and chloroform leaf extracts (ME and CE) and lupeol fraction (LF) of plant Crateva adansonii is investigated through employing in vivo male Wistar albino rat model. Acute toxicity study of C. adansonii ME and CE leaf extracts reveals that no mortality and no behavioral changes in experimental animals up to $2 \mathrm{~g} / \mathrm{kg}$. So no lethal dose we consider two optimal doses 200 and 400 mg of plant leaf extracts for in vivo inflammatory and analgesic study. In vivo acute and chronic anti-inflammatory activity was carried out through carrageenan-induced rat paw edema and cotton pellet-induced granuloma models. LF (100 mg/kg, oral route) of Crateva adansonii evoked highest percentage of inflammation inhibition (50 and 33.96\% respectively) in both in vivo acute and chronic inflammation model among all tested samples (ME and CE $200 \mathrm{mg}$ and $400 \mathrm{mg} / \mathrm{kg}$, oral route) including reference standard $(10 \mathrm{mg} / \mathrm{kg}$, oral route) indomethacin. Carrageenan-challenged experimental animals were screened for one inflammatory marker enzyme myeloperoxidase (MPO), inflammatory products such as Prostaglandrin $\mathrm{E}_{2}\left(\mathrm{PGE}_{2}\right.$ ), and eight different cytokines markers (TNFa, IL-6, IFN $\gamma$, IL-1a, IL-1 $\beta$, MCP-1, Rantes, and MIP) associated with inflammation reveals that LF $(100 \mathrm{mg} / \mathrm{kg}$, oral route) of Crateva adansonii shows prominent anti-inflammatory activity than reference standard indomethacin (10 mg/kg, oral route) over all these biological tested parameters. In vivo analgesic assays such as hot plate assay and acetic acid-induced writhing assay revealed that LF (100 mg/kg, oral route) possesses significant analgesic activity (11.60 s and 69.05\%) when compared with standard drug pentazocine $(10 \mathrm{mg} / \mathrm{kg}$, oral route). Finally, we made an in silico screening of lupeol against analgesic (nAChR) and anti-inflammatory (COX-2) target proteins reveals that lupeol possess highest binding affinity with $\mathrm{nAChR}$ and COX-2 target proteins $(-8.5$ and $-9.0 \mathrm{Kcal} / \mathrm{mol})$ over the reference standard pentazocine and indomethacin $(-7.0$ and $-8.4 \mathrm{Kcal} / \mathrm{mol})$ respectively.

Conclusion: The present study result provides a pharmacological evidences for analgesic and anti-inflammatory potential of lupeol isolated from Indian traditional plant Crateva adansonii act as a multi-target agent with immense anti-inflammatory potential targeting key molecules of inflammation such as MPO, PGE 2 , and eight proinflammatory cytokine markers. Outcome of present study is to find promising anti-inflammatory bioactive agents from the cheapest Indian traditional medicinal plant sources useful for pharmaceutical industries.

Keywords: Analgesic, Anti-inflammatory, Crateva adansonii, Lupeol

\section{Background}

Prime role of inflammation is to resolve the noxious stimuli such as pathogens, damaged cells, toxic compounds, or irradiation through body immune response and contribute tissue homeostasis [1], and store the inflamed cells through the healing process [2]. Inflammation is therefore considered as a protection mechanism to the body cells against such noxious stimuli [3]. This mitigation process depends on the delicate balance between pro-inflammatory and anti-inflammatory mediators secreted during inflammatory immune response. However, some mediators such as interleukin (IL)-12 possess both pro- and anti-inflammatory properties [4].

Anti-inflammatory key molecule involved in modulating inflammatory immune response is that transcriptional factor nuclear factor $\mathrm{\kappa} B(\mathrm{NF} \kappa \mathrm{B})$ play prime role in activating and synthesizing numerous proinflammatory cytokines such as IL-1 $\beta$, IL-6, and TNF- $\alpha$ and leads to tissue injury. NF- $\mathrm{kB}$ is found active in most of the inflammatory disease conditions such as inflammatory bowel disease, arthritis, sepsis, gastritis, asthma, and atherosclerosis [5]. In some disease conditions, NF$\mathrm{\kappa B}$ activators are produced which will cause inflammation of particular organ, i.e., elevation of osteoprotegerin causes over expression of NF- $\mathrm{kB}$ leads to cardiovascular disease and mortality [6]. NF- $\mathrm{BB}$ signaling controls gene expression of cyclooxygenases (COXs) for the decrease in prostaglandin (PG) production which consequently reduces pain and inflammation.

Anti-pyretic potential of non-steroidal antiinflammatory drugs (NSAIDs) are widely prescribed for analgesic and anti-inflammatory treatments. Chronic usage of NSAIDs causes major toxicity risk associated with renal failure and gastrointestinal problems. Medicinal plants contain promising wide range of compounds with different pharmaceutical activities [7]. Medicines from herbals are considered as valuable resource due to their low cost and lesser adverse effects [8, 9]. Numerous traditional medicinal plants and their phytocompounds are potent anti-inflammatory agents to treat various diseases linked with inflammation $[10,11]$.

Crateva adansonii is commonly known as garlic pear tree that belongs to Capparidaceae family. Leaves are trifoliate and flowers are white or cream color, bark is grey, and wood is yellowish-white in color. It is a moderate-sized deciduous tree distributed throughout India [12]. The plant parts such as leaf and bark were widely used as traditional medicine to treat many inflammatory diseases conditions. Crateva adansonii leaf extract also inhibit enzyme xanthine oxidase responsible 
for inflammatory arthritis [13]. Our previous study on phytocompound lupeol isolated from chloroform leaf extract of Indian traditional plant Crateva adansonii affirm their anti-inflammatory potential screened through in vitro and in silico approaches [14, 15]. Main objectives of the present study is to examines acute toxicity evaluation of Crateva adansonii leaf extracts and in vivo anti-inflammatory and analgesic potential of lupeol isolated from Indian traditional medicinal plant Crateva adansonii through kit assay quantification method for inflammatory marker enzyme myeloperoxidase, inflammatory product $\mathrm{PGE}_{2}$, and eight different cytokines associated with inflammation determined in serum samples of experimental animals.

\section{Methods}

\section{Plant extracts and lupeol fraction preparation}

Shade-dried healthy leaves (initial quantity $400 \mathrm{~g}$ ) of Crateva adansonii was pulverized into powder. Then the powder is used to prepare methanolic and chloroform leaf extracts of Crateva adansonii (ME, CE) using the soxhlet apparatus independently. Lupeol fraction (LF) (6 g with 15\%yield) containing marker compound of the plant lupeol is isolated from $40 \mathrm{~g}$ of $\mathrm{CE}$ using a silica gel glass column chromatography procedure (70-230 mesh size, $48 \times 2 \mathrm{~cm}$ ). Column elution was performed with $n$ hexane, ethyl acetate, and methanol solvents and the obtained fractions were subjected to TLC and confirm the existence of lupeol compound in the fraction and utilized for the study [15]. Three samples from Crateva adansonii ME, CE, and LF were used for further analysis.

\section{Animals and ethical clearance}

One hundred eighty-nine numbers of Wistar albino rats were purchased from CPCSEA registered breeder Kerala Verterinary University, Mannuthi, Kerala, India and utilized for the study. All experimental rats were 8 weeks old and weighs 180-250 g maintained at standard conditions of $30-70 \%$ humidity and $26 \pm 1{ }^{\circ} \mathrm{C}$ temperature in $12 \mathrm{~h}$ alternative dark/light cycles. All animals were allowed to feed with standard pelleted rat chaw. All the experimental protocols were done according to the Ethics Committee of Nandha College of Pharmacy, Erode, Tamilnadu, India (688/PO/Re/S/02/CPCSEA).

\section{Acute toxicity study}

Acute toxicity of $C$. adansonii leaf extracts was determined as per the OECD guideline test no 423 [16]. Wister albino rat was utilized for acute toxicity study. Animals administered with different doses (100-2000 $\mathrm{mg} / \mathrm{kg}$ ) of Crateva adansonii leaf extracts (ME and CE) using $0.1 \% \mathrm{CMC}$ as vehicle solution through peroral route were monitored for its behavioral and mortality rate, which will help to find out the lethality dose of the plant leaf extracts. Additional healthy control rat group was maintained without administering plant leaf extracts. For each leaf extract dose, three rats were employed then monitored for 3 days and mortality rate in two of three rats considered for acute toxicity evaluation whereas behavioral changes monitored and considered in all tested rats.

\section{Evaluation of in vivo anti-inflammatory activity Animal grouping and carrageenan-induced rat paw edema model}

Wistar albino rats were randomly split into seven groups from group I to group VII; each group has six animals $(n=6)$. Group I animals received vehicle $(0.1 \% \mathrm{CMC})$ through the intragastric tube (control), group II animals receive indomethacin $20 \mathrm{mg} / \mathrm{kg}$ (reference standard), whereas groups III-VI animals receive $200,400 \mathrm{mg} / \mathrm{kg}$ of $\mathrm{ME}$ and $\mathrm{CE}$ of $\mathrm{C}$. adansonii respectively, and group VII animals receive LF $100 \mathrm{mg} / \mathrm{kg}$ (per oral route). Acute anti-inflammatory potential of Crateva adansonii was determined by the standard carrageenan rat paw edema model [17]. Animals in all groups were administered and challenged with $1 \%$ carrageenan (solubilized in saline solution and injected into sub-planter region of rat). Experimental animals paw thickness was measured from 0 min to $3 \mathrm{~h}$ at every half an hour interval using a plethysmometer. Inhibition of rat paw thickness was measured and expressed in percentage for all experimental animals were recorded. The percentage of inhibition calculated by the following formula; \% Inhibition = 100 (1- Test mean paw thickness / control mean paw thickness).

\section{Cotton pellet-induced granuloma model}

Chronic anti-inflammatory activity of Crateva adansonii was determined using cotton pellet-induced granuloma model as per the standard method [18]. Briefly, sterile autoclaved two cotton pellets weighing $7 \mathrm{mg}$ implanted to anesthetized Wister albino rat in the dorsal region of each axilla. Totally, seven experimental groups and six rats were employed for each experimental group. Animal grouping and leaf sample, standard drug dosage is similar as that of carrageenan-induced rat paw model (group I control; group II indomethacin $20 \mathrm{mg} / \mathrm{kg}$; groups IIIVI ME and CE 200 and $400 \mathrm{mg} / \mathrm{kg}$; group VII LF 100 $\mathrm{mg} / \mathrm{kg}$ ). Further, $0.1 \% \mathrm{CMC}$ was utilized as vehicle solution administered through peroral route. All experimental animals were maintained in standard conditions up to 7 days after cotton pellet implantation. On the $8^{\text {th }}$ day, all animals were sacrificed using excess thiopental sodium to collect granulomatous tissues formed around the cotton pellet. The wet and dry weight of granulomatous tissues was recorded for each experimental animal 
group. Result values are statistically analyzed by Dunnett's " $t$ " test using GraphPad software and the values were considered significant at $p<0.05$.

\section{Determination of $P G E_{2}$ and cytokine marker levels in rat paw edema exudates}

Prostaglandin $\mathrm{E}_{2}\left(\mathrm{PGE}_{2}\right)$ level in carrageenan-challenged paw edema exudates were determined using the $\mathrm{PGE}_{2}$ ELISA kit assay. The experimental animals from the entire group were sacrificed using excess thiopental sodium after $3 \mathrm{~h}$; carrageenan challenge and hind paws were excised and inflammatory exudates were collected from centrifugation of excised hind paw [19]. In brief, a substrate solution was added to the assay wells and incubates for color development and the reaction is stopped to measure color intensity at $450 \mathrm{~nm}$. All the reagents and sample preparation was done as per the kit assay procedure [20].

Eight different inflammatory cytokine marker levels of rat paw edema exudates were determined using signosis Rat Inflammation ELISA strip assay (catalog no: EA4002). In brief, control or test samples were added and incubated to each well coated with primary antibody against cytokine then washed with assay buffer. Add biotin-labeled antibody to each well followed by streptavidin-HRP conjugate and substrate solution to incubate with gentle shaking for color development. The reaction was terminated by adding the stop solution. The density of the color developed was read at $450 \mathrm{~nm}$ using a microplate reader within $30 \mathrm{~min}$ of the assay. $\mathrm{PGE}_{2}$ level were expressed as $\mathrm{pg} / \mathrm{ml}$ of rat paw exudates whereas all other cytokine levels were expressed in relation to optical density at $450 \mathrm{~nm}$ of rat paw exudates.

\section{Myeloperoxidase enzyme assay}

Inflammatory marker enzyme MPO was assayed in rat paw edema tissues using the standard method with slight modification [21]. Rat paw tissues was homogenized using $10 \%$ phosphate buffer then centrifuged and collect supernatant used for MPO assay. In brief, a known aliquot of the sample was mixed with phosphate buffer containing $O$-dianisidinedihydrochloride and hydrogen peroxide. The sample absorbance was measured spectrophotometrically at $460 \mathrm{~nm}$ and their triplicate results were recorded. MPO level were expressed as $\mathrm{U} / \mathrm{mg}$ of rat paw tissue protein.

\section{Evaluation of in vivo analgesic activity Hot plate assay}

Hot plate assay is used to evaluate the analgesic activity of Crateva adansonii plant leaf extracts and its lupeol fraction was done as per the previously reported standard method [22]. Totally, seven experimental groups and six rats were employed for each experimental group. Animal grouping and leaf sample dosage is similar as that of carrageenan induced rat paw model with exception of $10 \mathrm{mg} / \mathrm{kg}$ of pentazocine employed as a standard drug (group I control; group II pentazocine $10 \mathrm{mg} / \mathrm{kg}$; group III-VI ME and CE 200 and $400 \mathrm{mg} / \mathrm{kg}$; group VII LF $100 \mathrm{mg} / \mathrm{kg}$ ) administered through peroral route. In brief hot plate, temperature was maintained at $55 \pm 0.5$ ${ }^{\circ} \mathrm{C}$. The time taken for a mouse to shake, lick, or jumping of the hind paw is considered as pain indicators. The pre-treatment reaction time of each mouse was recorded initially before sample administration. Animal groups were administered orally for six consecutive days as per the dosage form as in anti-inflammatory assay. Posttreatment reaction time for each animal is recorded at $30,60,90,120$ min on $7^{\text {th }}$ day after oral administration. The percentage of inhibition is calculated by the difference between post-treatment and pre-treat time divided by pre-treatment time.

\section{Acetic acid-induced writhing assay}

Acetic acid-induced writhing assay is used to evaluate analgesic activity of Crateva adansonii. Totally, seven experimental groups and six rats were employed for each experimental group. Animal grouping and leaf

Table 1 Acute anti-inflammatory activity of Crateva adansonii leaf extracts and its Lupeol containing LF in male Wistar albino rat

\begin{tabular}{|c|c|c|c|c|c|c|c|c|c|}
\hline \multirow[t]{2}{*}{ Groups } & \multirow[t]{2}{*}{ Drug Treatment } & \multicolumn{7}{|c|}{ Paw thickness in $\mathrm{mm}$} & \multirow{2}{*}{$\begin{array}{l}\% \\
\text { Inhibition } \\
\text { at } 3 \mathrm{~h}\end{array}$} \\
\hline & & $\mathrm{Oh}$ & $1 / 2 h$ & $1 \mathrm{~h}$ & $11 / 2 h$ & $2 \mathrm{~h}$ & $2 \frac{1}{2} h$ & $3 \mathrm{~h}$ & \\
\hline | & Control $0.1 \%$ CMC & $1.8 \pm 0.02$ & $3.6 \pm 0.02$ & $5.2 \pm 0.04$ & $6.2 \pm 0.02$ & $5.4 \pm 0.02$ & $4.8 \pm 0.02$ & $4.1 \pm 0.02$ & - \\
\hline$\|$ & Indomethacin 20 mg/kg & $1.6 \pm 0.04$ & $2.4 \pm 0.04^{* *}$ & $2.9 \pm 0.01^{* *}$ & $3.2 \pm 0.01^{* *}$ & $2.8 \pm 0.01^{* *}$ & $2.5 \pm 0.04^{* *}$ & $2.0 \pm 0.01^{*}$ & 48 \\
\hline III & ME 200 mg/kg & $1.1 \pm 0.02$ & $2.8 \pm 0.04^{* *}$ & $3.2 \pm 0.04^{* *}$ & $3.6 \pm 0.04^{* *}$ & $3.3 \pm 0.02^{* *}$ & $2.9 \pm 0.02^{*}$ & $2.5 \pm 0.01^{* *}$ & 42 \\
\hline IV & ME 400 mg/kg & $1.4 \pm 0.04$ & $2.6 \pm 0.01^{* *}$ & $3.1 \pm 0.01^{* *}$ & $3.4 \pm 0.03^{* *}$ & $3.0 \pm 0.01^{* *}$ & $2.6 \pm 0.01^{* *}$ & $2.2 \pm 0.01^{* *}$ & 45 \\
\hline V & CE 200 mg/kg & $1.4 \pm 0.02$ & $3.4 \pm 0.01^{*}$ & $4.0 \pm 0.02^{* *}$ & $4.4 \pm 0.04^{* *}$ & $3.6 \pm 0.02^{* *}$ & $3.1 \pm 0.02^{* *}$ & $2.6 \pm 0.03^{* *}$ & 29 \\
\hline VI & CE 400 mg/kg & $1.2 \pm 0.01$ & $2.9 \pm 0.02^{* *}$ & $3.4 \pm 0.02^{*}$ & $3.8 \pm 0.02^{* *}$ & $3.2 \pm 0.04^{* *}$ & $2.9 \pm 0.04^{* *}$ & $2.5 \pm 0.02^{*}$ & 39 \\
\hline VII & LF 100 mg/kg & $1.5 \pm 0.03$ & $3.0 \pm 0.03^{* *}$ & $3.1 \pm 0.01^{* *}$ & $3.1 \pm 0.01^{* *}$ & $2.7 \pm 0.01^{* *}$ & $2.2 \pm 0.02^{* *}$ & $1.8 \pm 0.03^{* *}$ & 50 \\
\hline
\end{tabular}

The data are presented as mean $\pm \mathrm{SEM}, n=6,{ }^{*} p<0.05,{ }^{* *} p<0.01 \mathrm{vs}$. control. Data were analyzed by using one-way ANOVA followed by Dunnett's " $t$ " test using the software Graph Pad

ME Methanolic extract of $C$. adansonii leaf, CE Chloroform extract of C. adansonii leaf, LF Lupeol fraction 


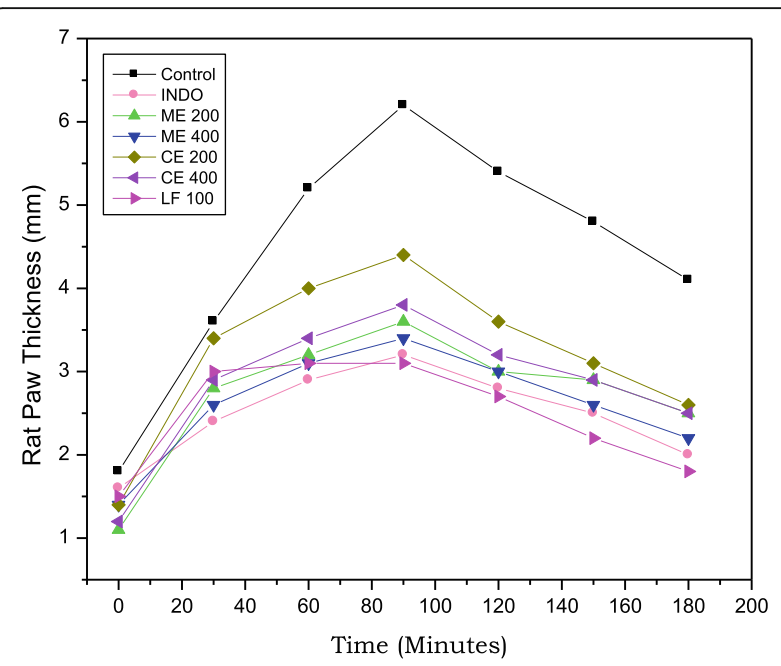

Fig. 1 Rat paw thickness ( $\mathrm{mm}$ ) of experimental animal groups at different time intervals assessed through acute anti-inflammatory activity

sample, standard drug dosage is similar as that of carrageenan-induced rat paw model (group I control; group II pentazocine $10 \mathrm{mg} / \mathrm{kg}$; group III-VI ME and CE 200 and $400 \mathrm{mg} / \mathrm{kg}$; group VII LF $100 \mathrm{mg} / \mathrm{kg}$ ) administered through peroral route. In brief, each experimental animal mouse was administered with $1 \%$ acetic acid $(1 \mathrm{ml} / 100 \mathrm{~g})$ intraperitoneally. The mice were observed for writhes and the total number of writhes in control and treated group animal for 20 min after the last injection is recorded. Percentage of analgesic activity is calculated by the difference between writhing count of control and treated groups divided by writhes in control groups. Statistical data were analyzed by using one-way ANOVA followed by Dunnett's " $t$ " test using the software Graph Pad and results values were considered significant $(p<0.05)$.

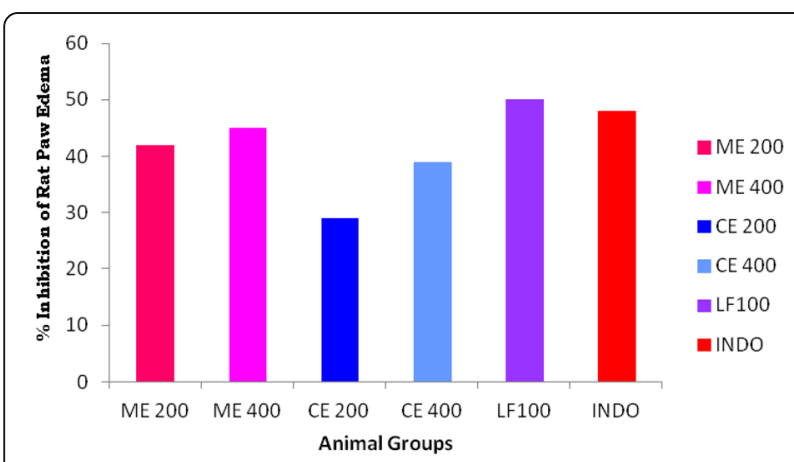

Fig. 2 Percentage of Inflammation inhibition by Crateva adansonii leaf extracts, lupeol fractions (ME, CE, and LF), and reference standard in Caragennan induced rat paw edema model

\section{Molecular docking study}

Autodock (Version 4) was employed for the present study and the calculations were carried out by Autodock tools [23]. Receptor-ligand obtained are ranked using an energy-based scoring functions. 3D crystal structures of nicotinic acetylcholine receptor $\mathrm{nAChR}$ (PDB 2KSR) as analgesic target and COX-2 enzyme receptor (PDB $6 \mathrm{COX})$ as inflammatory molecular targets was retrieved from Protein data Base (PDB www.rcsb.org). Lupeol and reference drug for analgesic and inflammatory protein targets such as pentazocine and indomethacin 2D structures were retrieved from PubChem database (https:// pubchem.ncbi.nlm.nih.gov/) [24]. Retrieved 2D SDF file formats were submitted to "Online SMILES convertor and Structure file generator" and converted into standard 3D PDB formats for further in silico analysis [25]. The grid map that represents the protein binding sites for docking was calculated using AutoGrid. The grid size of $98 \times 74 \times 76$ points in each dimension was set for COX-2; the grid size for $\mathrm{nAChR}$ was set to $31 \times 60 \times 62$ points in each dimension covers entire target protein. The grid points space $(0.375 \AA)$ was set by using AutoGrid and Gasteiger charges were measured by AutoDock tools. Assessment of docking ( 100 times), size of population (150), energy evaluation (maximum number 250, 000) generations (maximum number 27,000), rate of mutations (0.02), rate of cross-over (0.8), value of elitism (1), and other parameters as default values were established using the autotors utility of the AutoDock tool. The results of molecular docking studies and their molecular protein target-drug interactions were visualized and analyzed using receptor-ligand interaction options in Discovery Studio v2.5 software.

\section{Result}

\section{Acute toxicity study}

Acute toxicity study was conducted to determine the safe dosage of pharmacologically active principles from plant extracts to animal and human subjects. In the present study, Wister albino rats were employed and administered with different doses of two different leaf extracts (ME and CE) of Crateva adansonii to test their lethality. There are no marked behavior changes and zero mortality rate in all tested male Wister albino rat administered with ME and CE leaf extracts up to 2000 $\mathrm{mg} / \mathrm{kg}$ body weight. Results proved that the administration of ME and CE from Crateva adansonii up to the 2 $\mathrm{g} / \mathrm{kg}$ dose were safe to be used for our various antiinflammatory investigations through in vivo model, in a single administration. So we have chosen two optimal concentrations (200 and $400 \mathrm{mg} / \mathrm{kg}$ ) for both $\mathrm{ME}$ and CE plant leaf extracts, whereas dosage of $100 \mathrm{mg} / \mathrm{kg} \mathrm{LF}$ is used for further anti-inflammatory and analgesic study. 
Table 2 Chronic anti-inflammatory activity of Crateva adansonii leaf extracts and its Lupeol containing LF in male Wister albino rat

\begin{tabular}{llllll}
\hline Groups & Drug treatment & Wet qWEIGHT $(\mathbf{m g})$ & Dry weight $(\mathbf{m g})$ & Transudative weight (mg) & Percentage inhibition \\
\hline I & Control 0.1\%CMC & $214.66 \pm 8.36$ & $58.62 \pm 1.69$ & 156.04 & - \\
II & Indomethacin $(20 \mathrm{mg} / \mathrm{kg})$ & $159.44 \pm 5.32^{*}$ & $42.69 \pm 2.27^{*}$ & $116.75^{* *}$ & 25.18 \\
III & ME $200 \mathrm{mg} / \mathrm{kg}$ & $186.67 \pm 7.38$ & $47.55 \pm 1.97$ & 139.12 & 10.84 \\
IV & ME $400 \mathrm{mg} / \mathrm{kg}$ & $167.26 \pm 6.34^{*}$ & $41.33 \pm 2.26^{*}$ & $125.93^{*}$ & 19.29 \\
V & CE $200 \mathrm{mg} / \mathrm{kg}$ & $180.62 \pm 3.77$ & $46.30 \pm 3.15$ & 134.32 & 13.92 \\
VI & CE $400 \mathrm{mg} / \mathrm{kg}$ & $162.47 \pm 6.37^{*}$ & $41.66 \pm 1.96^{*}$ & $120.81^{*}$ & 22.58 \\
VII & LF $100 \mathrm{mg} / \mathrm{kg}$ & $155.36 \pm 5.75^{*}$ & $52.31 \pm 2.55^{*}$ & $103.05^{* *}$ & 33.96
\end{tabular}

The data are presented as mean \pm SEM $n=6 .{ }^{*} p<0.05,{ }^{* *} p<0.01$ vs. control. Data were analyzed by using one-way ANOVA followed by Dunnett's " $t$ " test using the software Graph Pad

ME Methanolic extract of C. adansonii leaf, CE Chloroform extract of C. adansonii leaf, LF Lupeol fraction

\section{Evaluation of in vivo anti-inflammatory activity Carrageenan-induced rat paw edema model}

The results of paw thickness differences in mm obtained from Carrageenan-induced rat paw edema in vivo model were depicted in Table 1 and Fig. 1. The maximal percentage of rat paw inhibition (50\%) was recorded in group VII animals receiving LF than group II animals receiving reference standard indomethacin shows $48 \%$ of inhibition in rat paw edema. Experimental animals from groups III and IV receiving methanolic leaf extract of the plant shows $42 \%$ and $45 \%$ of rat paw edema inhibition at $3 \mathrm{~h}$ respectively. Whereas animals from groups $\mathrm{V}$ and VI receiving chloroform leaf extracts of C. adansonii shows $29 \%$ and $39 \%$ of rat paw edema inhibition respectively at $3 \mathrm{~h}$ (Fig. 2).

\section{Cotton pellet induced granuloma model}

Chronic anti-inflammatory potential of Crateva adansonii was analyzed by cotton pellet-induced granuloma in vivo model and their results were presented in Table 2 and Fig. 3. Wet, dry, and transudative weights are measured for each experimental animal groups. Highest wet, dry, and transudative weights (214.66 mg, $58.62 \mathrm{mg}$, and $156.04 \mathrm{mg}$ respectively) were monitored in group I control animal receiving

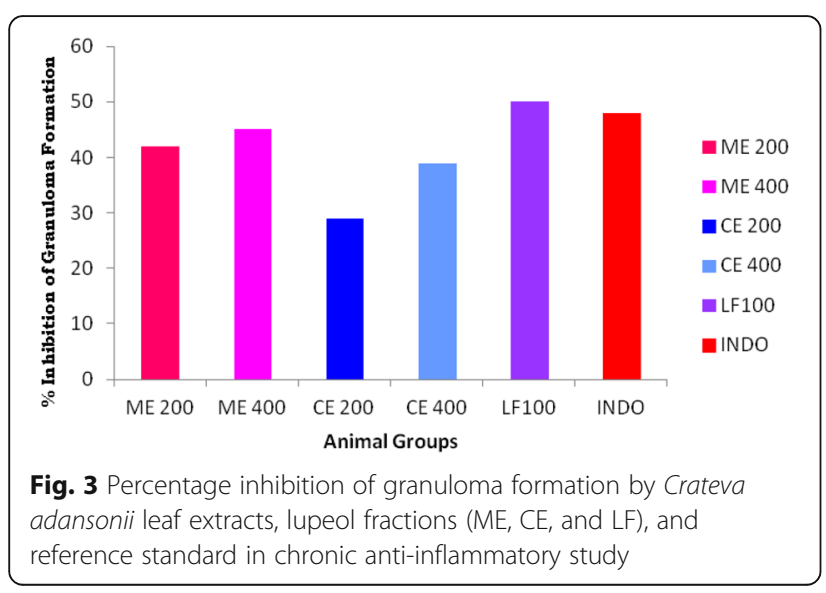

$0.5 \% \mathrm{CMC}$ as a vehicle control. The highest percentage of inhibition (33.96\%) was measured in group VII animals receiving LF than all other tested animal groups ranging from 10.84 to $25.18 \%$ of granuloma inhibition.

\section{Determination of $P G E_{2}$ level and cytokine marker levels}

The level of prostaglandin $\mathrm{E}_{2}$ was measured in exudates collected from experimental animal paws and their results were presented in Fig. 4a. "Prostaglandin $\mathrm{E}_{2}$ level in control animals is increased four-fold" when compared with the experimental animal groups receiving lupeol fractions (LF). Group II to VII experimental animal receiving Crateva adansonii plant leaf extracts and its lupeol fractions shows the significant dosedependent reduction of $\mathrm{PGE}_{2}$ level $35,75,55,68,46$, and $32 \%$ of inhibition respectively. These result findings served as a benchmark to prove the anti-inflammatory potential of leaf extracts and its fraction (ME, CE, and LF) for efficient blocking of the prostaglandin inflammatory pathway.

Eight cytokine inflammatory markers such as interferon-gamma (IFNy), interleukin-1alpha, beta (IL$1 \alpha$ and $1 \beta$ ), interleukin-6 (IL-6), tumor necrosis factor alpha (TNF $\alpha$ ), macrophage inflammatory protein (MIP), monocyte chemoattractant protein-1 (MCP-1), and regulated upon activation normal $\mathrm{T}$ cell expressed and presumably secreted (RANTES) were analyzed by Rat Signosis ELISA assay, and the results were presented in Fig. 4b-i. Marked reduction of eight inflammatory cytokines levels of test group's animal receiving $\mathrm{ME}, \mathrm{CE}$, and LF than the animals receiving reference indomethacin. LF causes nearly 2- to 4-fold fall in all inflammatory cytokine absorbance level at $450 \mathrm{~nm}$ when compared with all other tested samples and reference indomethacin. Among all tested groups, experimental animals receiving a dose of $100 \mathrm{mg} / \mathrm{kg}$ LF show a potential reduction in cytokine levels except IL-1 $\beta$.

\section{Assessment of myeloperoxidase activity}

Inflammatory marker enzyme myeloperoxidase (MPO) level was assessed in carrageenan-challenged experimental 

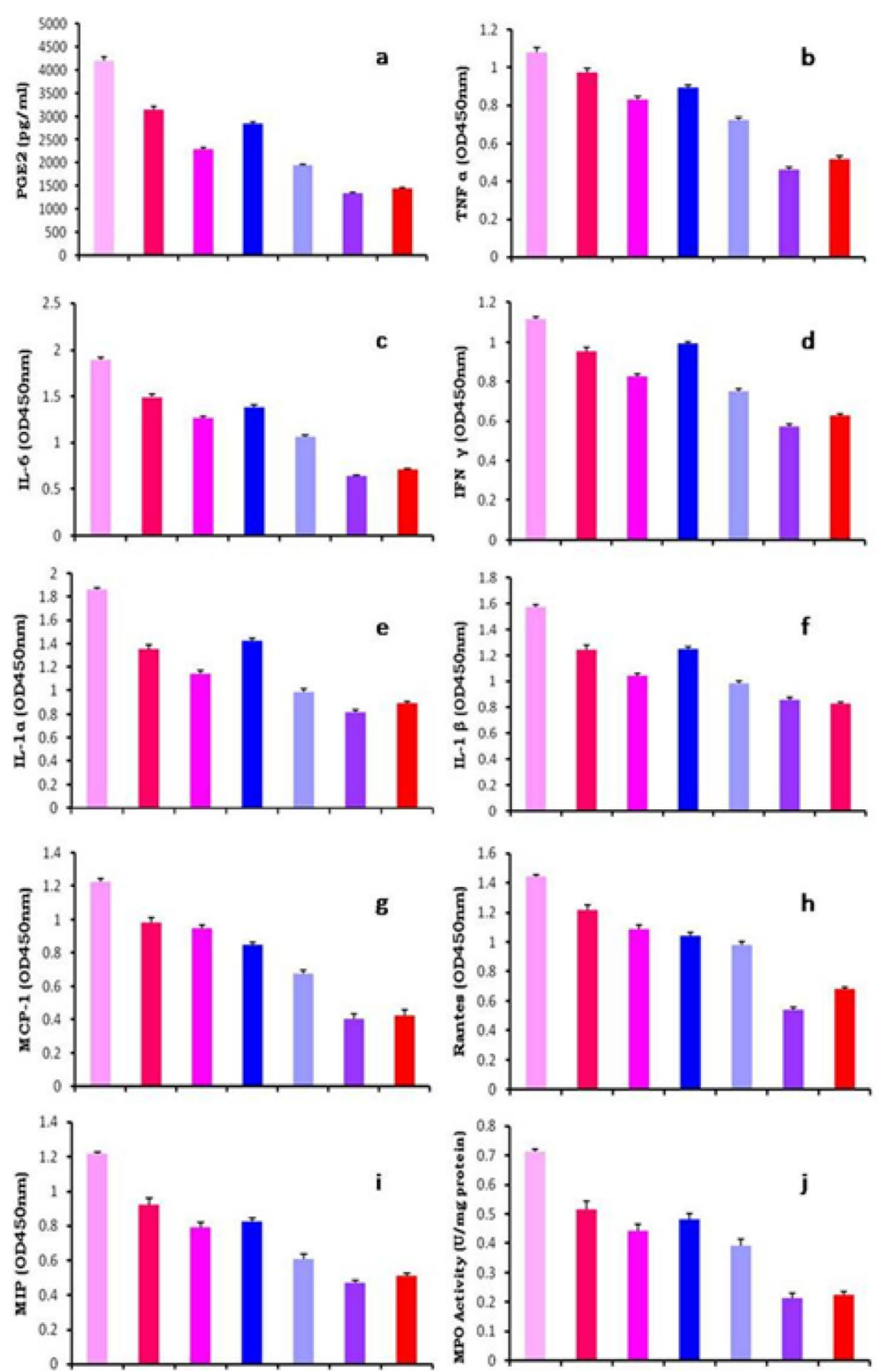

Control

口 ME 200

- ME400

- CE200

CE400

- LF 100

- INDO

Fig. 4 a-j Inflammatory enzymes (PGE2 and MPO) and cytokines levels of Carrageenan challenged animals

animals and their results were depicted in Fig. 4j. Group VII experimental animals receiving lupeol fractions resulted in 4fold of MPO enzyme activity inhibition when compared with the control group animal enzyme activity. Animals receiving LF show significant reduction in MPO enzyme production when compared with all other tested group animals including reference indomethacin.

\section{Evaluation of in vivo analgesic activity Hot plate assay}

The results of hot plate assay of experimental animals receiving Crateva adansonii leaf extracts and its LF fractions were displayed in Table 3 and Fig. 5. Animals receiving LF shows a significant $(p<0.001)$ analgesic effect when compared with all other tested groups. LFtreated animal shown remarkable pain threshold values at each time interval after $30,60,90$, and $120 \mathrm{~min}(8.40$, $10.06,11.45$, and $11.60 \mathrm{~s}$ respectively) which is very closer to the pain threshold times of narcotic pentazocine standard $(9.66,10.35,11.63$, and $10.76 \mathrm{~s}$ respectively), whereas the chloroform leaf extract receiving animals shows considerable analgesic activity compared to the animals receiving methanolic leaf extracts. Further study reveals that LF from Crateva adansonii reveals 
Table 3 Effect of Crateva adansonii leaf extracts and its Lupeol containing LF on hot plate assay in mice

\begin{tabular}{|c|c|c|c|c|c|}
\hline \multirow[t]{2}{*}{ Groups } & \multirow[t]{2}{*}{ Drug treatment } & \multicolumn{4}{|c|}{ Pain threshold (in s) } \\
\hline & & $30 \mathrm{~min}$ & $60 \mathrm{~min}$ & $90 \mathrm{~min}$ & $120 \mathrm{~min}$ \\
\hline । & Control $0.1 \% C M C$ & $4.02 \pm 0.02$ & $5.33 \pm 0.14$ & $5.77 \pm 0.09$ & $5.65 \pm 0.12$ \\
\hline$\|$ & Pentazocine 10 mg/kg & $9.66 \pm 0.11^{* *}$ & $10.35 \pm 0.92^{* * *}$ & $11.63 \pm 0.60^{* * *}$ & $10.76 \pm 0.06^{* * *}$ \\
\hline III & ME 200 mg/kg & $5.08 \pm 0.22$ & $6.09 \pm 0.55$ & $6.23 \pm 0.24$ & $5.96 \pm 0.40$ \\
\hline IV & ME 400 mg/kg & $6.66 \pm 0.12$ & $8.47 \pm 0.22^{*}$ & $7.30 \pm 0.45^{*}$ & $7.28 \pm 0.40^{*}$ \\
\hline V & CE 200 mg/kg & $6.31 \pm 0.09$ & $8.06 \pm 0.07^{*}$ & $8.76 \pm 0.22^{*}$ & $8.54 \pm 0.05^{*}$ \\
\hline VI & CE 400 mg/kg & $7.45 \pm 0.54^{*}$ & $9.60 \pm 0.22^{* *}$ & $9.10 \pm 0.43^{* *}$ & $10.22 \pm 0.32^{* * *}$ \\
\hline VII & LF 100mg/kg & $8.40 \pm 0.15^{* *}$ & $10.06 \pm 0.88^{* * *}$ & $11.45 \pm 0.22^{* * *}$ & $11.60 \pm 0.96^{* * *}$ \\
\hline
\end{tabular}

The data are presented as mean \pm SEM $n=6 .{ }^{*} p<0.05,{ }^{* *} p<0.01$, and ${ }^{* * *} p<0.001$ vs. control. Data were analyzed by using one-way ANOVA followed by Dunnett's " $t$ " test using the software Graph Pad

ME Methanolic extract of $C$. adansonii leaf, CE Chloroform extract of $C$. adansonii leaf, LF Lupeol fraction

equipotent pain inhibition at 30,60, and $90 \mathrm{~min}$ with standard, but at the end $120 \mathrm{~min}$, LF shows highest pain threshold time $11.60 \pm 0.96 \mathrm{~s}$ and $10.76 \pm 0.06 \mathrm{~s}$ respectively than standard pentazocine.

\section{Acetic acid-induced writhing assay}

Acetic acid-induced writhing assay results were shown in Table 4. It reveals that LF possesses equipotent analgesic activity (69.05\%) when compared with reference standard indomethacin $(70.05 \%)$. Highly significant $(p<0.001)$ analgesic activity with less writhing count was seen in the standard group (19.60 \pm 0.95$)$ followed by the LF group $(20.26 \pm 0.98)$ and group VI experimental $(25.35 \pm 1.55)$ animals.

\section{Molecular docking analysis}

Lupeol exhibited highest binding affinity and docking score $-9.0 \mathrm{Kcal} / \mathrm{mol}$ against inflammatory COX-2 and - $8.5 \mathrm{Kcal} / \mathrm{mol}$ against analgesic (nAChR) protein targets over their reference standard drugs pentazocine -7.0 $\mathrm{Kcal} / \mathrm{mol}$ and indomethacin $-8.4 \mathrm{Kcal} / \mathrm{mol}$ with $\mathrm{nAChR}$ and COX-2 receptors respectively (Table 5 ). High binding affinity of lupeol with inflammatory marker enzyme Cycloxygenase-2 (COX-2) is favored by the alkyl and hydrogen bonded interactions with COX-2 residues of Arg44, Tyr373, Pro542, and Arg61 respectively. Similarly lupeol form alkyl interactions with Ile33, Ile36, Ile77, Val91, Tyr94 residues of analgesic nicotinic acetyl choline receptor. Whereas reference standard indomethacin possess one hydrogen bonded interactions Gln203 and three alkyl bonded His207, Lys211, Val291 interactions with COX-2 enzyme, similarly pentazocine possess alkyl interactions with Pro38, Cys39, Ile42, Leu68, Ala69, Leu70, Val72, Phe73 residues of analgesic receptor nAChR (Figs. 6, 7, 8, and 9).

\section{Discussion}

In our present study, we seek the pharmacological evidence for analgesic and anti-inflammatory potential of lupeol isolated from Crateva adansonii leaf extract which was proven through different in vivo model study in order to promote the cheapest source of key antiinflammatory molecule from natural origin and alternate the existing NSAIDs drug usage for chronic inflammatory diseases. Natural products from medicinal plants are likely to be safe without any compromising health effect, and thus widely used as self-medication [26]. However, the safety and toxicity assessment of natural products is done through OECD guidelines to provide scientific evidence for human consumption, which is being carried out in various experimental animal models to evaluate their safety for future human use [27].

After carrageenan stimulation, paw thickness of experimental animals is increased gradually up to $0-3 \mathrm{~h}$ which is due to the biphasic inflammatory mechanism which leads to the activation and accumulation of inflammatory mediators. Initial (within $6 \mathrm{~h}$ ) and final (after $6 \mathrm{~h}$ ) phase causes the inducible nitric oxide synthase (iNOS) and COX-2 enzyme elevation respectively. Carrageenan-induced rat paw edema method is a widely employed method to investigate preliminary screening method to assess and measure the anti-inflammatory effect of natural products [28, 29]. Carrageenan is a sulfated polysaccharide substance used to produce inflammatory immune response in experimental animals leading to the release of pro-inflammatory mediators such as prostaglandin, histamine, bradykinin, leukotrienes, etc. [30]. The mechanism of carrageenan-induced inflammation in two-phase response, serotonin, and histamine released during the first phase followed by the release of prostaglandins, lysosome enzymes during the second phase [31-33]. Chloroform leaf extract fraction (LF) of C. adansonii shown maximal percentage $(50 \%)$ of inhibition of rat paw thickness at $3 \mathrm{~h}$ and it efficiently blocks later phase pro-inflammatory cytokines release in acute inflammation model. The LF possess marker phytocompound of the plant; lupeol act as clinically 


\section{Hot Plate Assay}

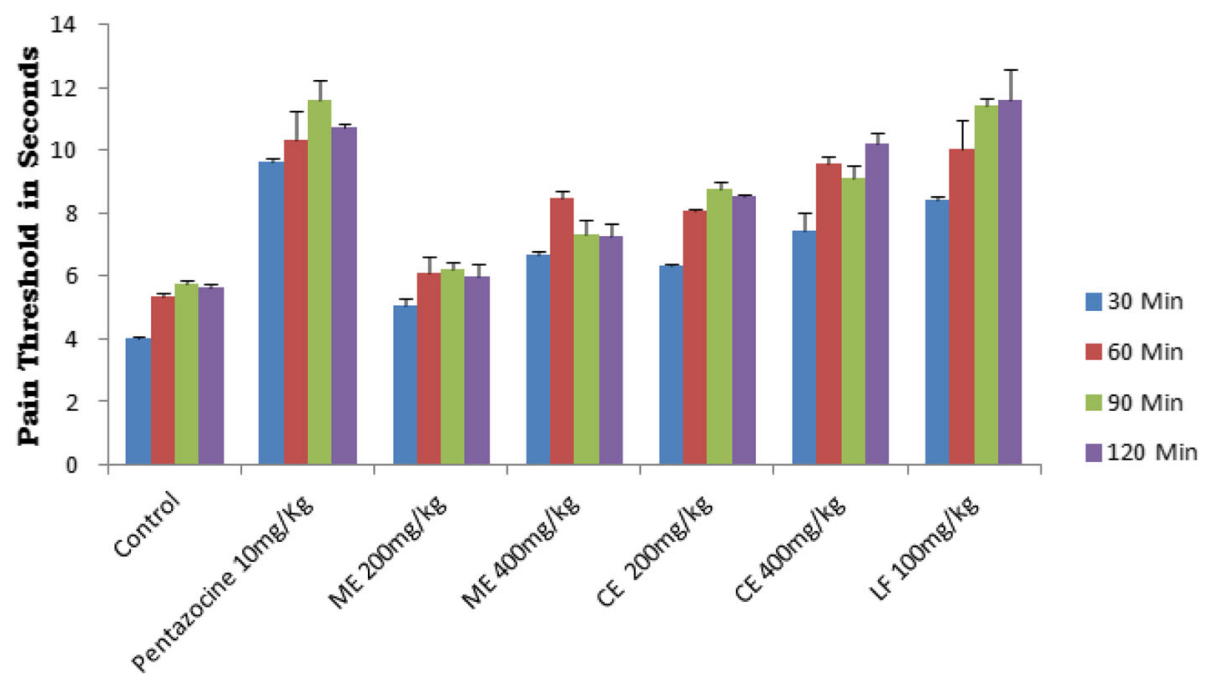

Animal Groups

Fig. 5 Effect of Crateva adansonii leaf extracts and its Lupeol containing LF on hot plate assay in mice

active anti-inflammatory agent block proinflammatory cytokines and enzymes [34].

Cotton pellet-induced granuloma model is a routinely employed standard method to assess chronic antiinflammation activity of natural compounds; dry and wet weight of cotton pellet is used to measure the granulomatous tissue formation. Administration of Crateva adansonii leaf extracts and leaf extract fraction has been observed to inhibit the granulomatous tissue formation; ultimately, it reduces the weight of wet cotton pellets in a dose-dependent manner remarkably the LF produced more inhibitory effect in granulomatous tissue formation than the reference standard. The amount of granulomatous tissue formed is directionally proportional to the rate of accumulation of inflammatory products such as macrophages, neutrophils, fibroblasts, etc. $[35,36]$. The degree of the anti-inflammatory effect of the sample is directly proportional to the percentage of inhibition of granulomatous tissue formation. Group VII animals (33.96\% inhibition) receiving LF appears to be more potent than group II animals $(25.18 \%)$ receiving reference standards in inhibiting the dry weight of cotton pellets. Triterpenes found to stabilize mast cell membranes and inhibit the infiltration of the number of inflammatory cells at the site of inflammation [37]. Chloroform leaf extract fraction (LF) of Crateva adansonii possess marker triterpene compound namely lupeol may be responsible for the marked anti-proliferative effect on granulomatous tissue formation. Crateva adansonii plant marker compound lupeol was found to inhibit transcriptional factor NF- $\mathrm{kB}$ and other molecular targets of inflammation [38].

LF significantly offset the carrageenan-induced $\mathrm{PGE}_{2}$ production in paw edema exudates of group VII animals. Prostaglandin $E_{2}$ is a major inflammatory mediator involved in most of the inflammatory disease conditions,

Table 4 Effect of Crateva adansonii leaf extracts and its Lupeol containing LF on acetic acid-induced writhing in mice

\begin{tabular}{llll}
\hline Groups & Drug treatment & Writhing count for $\mathbf{2 0}$ min & Percentage of analgesic activity \\
\hline I & Control 0.1\%CMC & $65.45 \pm 2.50$ & - \\
II & Indomethacin $20 \mathrm{mg} / \mathrm{kg}$ & $19.60 \pm 0.95^{* * *}$ & $70.05 \%$ \\
III & ME $200 \mathrm{mg} / \mathrm{kg}$ & $48.33 \pm 2.22^{*}$ & $26.16 \%$ \\
IV & ME $400 \mathrm{mg} / \mathrm{kg}$ & $38.671 .75^{* *}$ & $40.92 \%$ \\
V & CE $200 \mathrm{mg} / \mathrm{kg}$ & $36.76 \pm 2.22^{* *}$ & $43.83 \%$ \\
VI & CE $400 \mathrm{mg} / \mathrm{kg}$ & $25.35 \pm 1.55^{* * *}$ & $61.26 \%$ \\
VII & LF $100 \mathrm{mg} / \mathrm{kg}$ & $20.26 \pm 0.98^{* * *}$ & $69.05 \%$ \\
\hline
\end{tabular}

The data are presented as mean \pm SEM $n=6 .{ }^{*} p<0.05,{ }^{* *} p<0.01$, and ${ }^{* * *} p<0.001$ vs. control. Data were analyzed by using one-way ANOVA followed by Dunnett's " $t$ " test using the software Graph Pad

ME Methanolic extract of C. adansonii leaf, CE Chloroform extract of C. adansonii leaf, LF Lupeol fraction 
Table 5 Binding affinity and molecular interactions of Lupeol and reference standard drug against analgesic and inflammatory target proteins

\begin{tabular}{lll}
\hline Docking complex & Binding affinity Kcal/mol & Residues involved in interaction \\
\hline COX-2-Lupeol & -9.0 & Arg44,Arg61*,Tyr373,Pro542 \\
COX-2-Indomethacin & -8.4 & Gln203*,His207,Lys211,Val291 \\
nAChR-Lupeol & -8.5 & Ile33,lle36,lle77,Val91,Tyr94,Met155 \\
nAChR-Pentazocine & -7.0 & Pro38,Cys39,Ile42,Leu68,Ala69,Leu70,Val72,Phe73
\end{tabular}

Residues with * symbol indicates the hydrogen bonded interactions

Residues without any symbol indicates Alkyl bonded interactions

so the inhibition of $\mathrm{PGE}_{2}$ is considered as the best way to treat most of the diseases associated with inflammation [39]. Prevention of neutrophils infiltration at inflammation site is monitored through myeloperoxidase enzyme level in experimental animals serum of rat paw edema model revealed that lupeol fraction from Crateva adansonii evoke excellent MPO inhibition than reference standard animal group. Taken together, inhibition of inflammatory enzyme ( $\mathrm{PGE}_{2}$ and $\mathrm{MPO}$ ) and proinflammatory cytokines by Crateva adansonii leaf extracts and lupeol fractions could negatively affect monocyte and leukocyte migration, which is scientifically evidenced by the hidden molecular mechanisms of the anti-inflammatory effect of the plant Crateva adansonii.

Group VII experimental animals receiving LF shows a significant reduction of cytokine levels, which once again proves the potential of LF in blocking inflammatory cytokine production cascade over the reference standard. Cytokines act as a biomarker for different inflammatory disease conditions and their cut off values will help to diagnose particular inflammatory disease conditions [40].

Protective effect of lupeol fractions against the carrageenan-induced rat paw edema is observed through screening of various inflammatory markers in the study. Lupeol fraction of Crateva adansonii inhibit and suppress tumor necrosis factor- $\alpha$ (TNF- $\alpha$ ) and IL-1 $\beta$ [41]. Both TNF- $\alpha$ and interleukin-1 (IL-1) play major role in pathogenesis of inflammatory disorders such as rheumatoid arthritis. These proinflammatory cytokines and interleukins are involved in osteoclast differentiation, inflammation, and bone erosion [42]. Reduction of these inflammatory mediators will prevent side effect and further clinical manifestation of arthritic inflammations. TNF- $\alpha$ is an important inflammatory cytokine marker activates the expression of other cytokines, chemokines, adhesion molecules, and neutrophil [43]. So the effect of LF from Crateva adansonii on TNF- $\alpha$ was investigated. It was shown that LF causes significant reduction of TNF- $\alpha$, IL-1, and IL- 6 cytokine levels which could inhibit the infiltration and activation of macrophage at

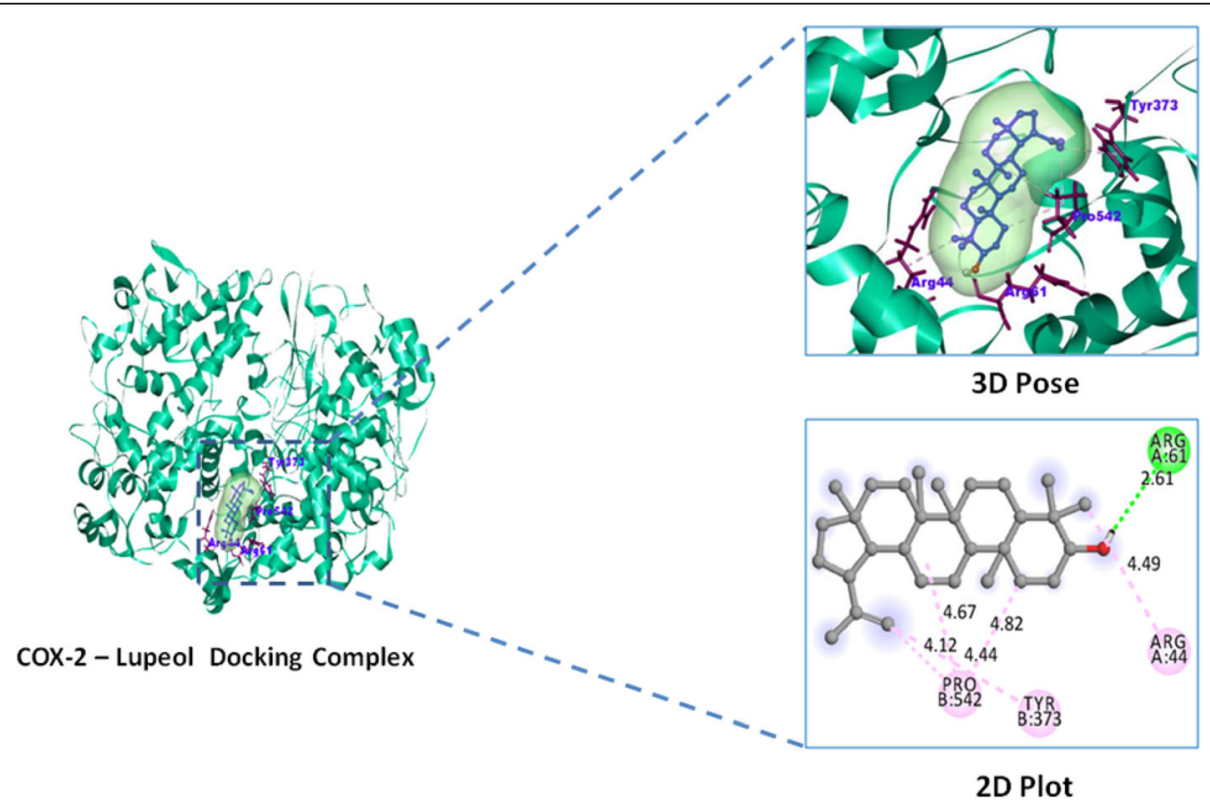

Fig. 6 Inflammatory receptor COX-2-Lupeol docking complex 3D pose and their 2D interaction plot 


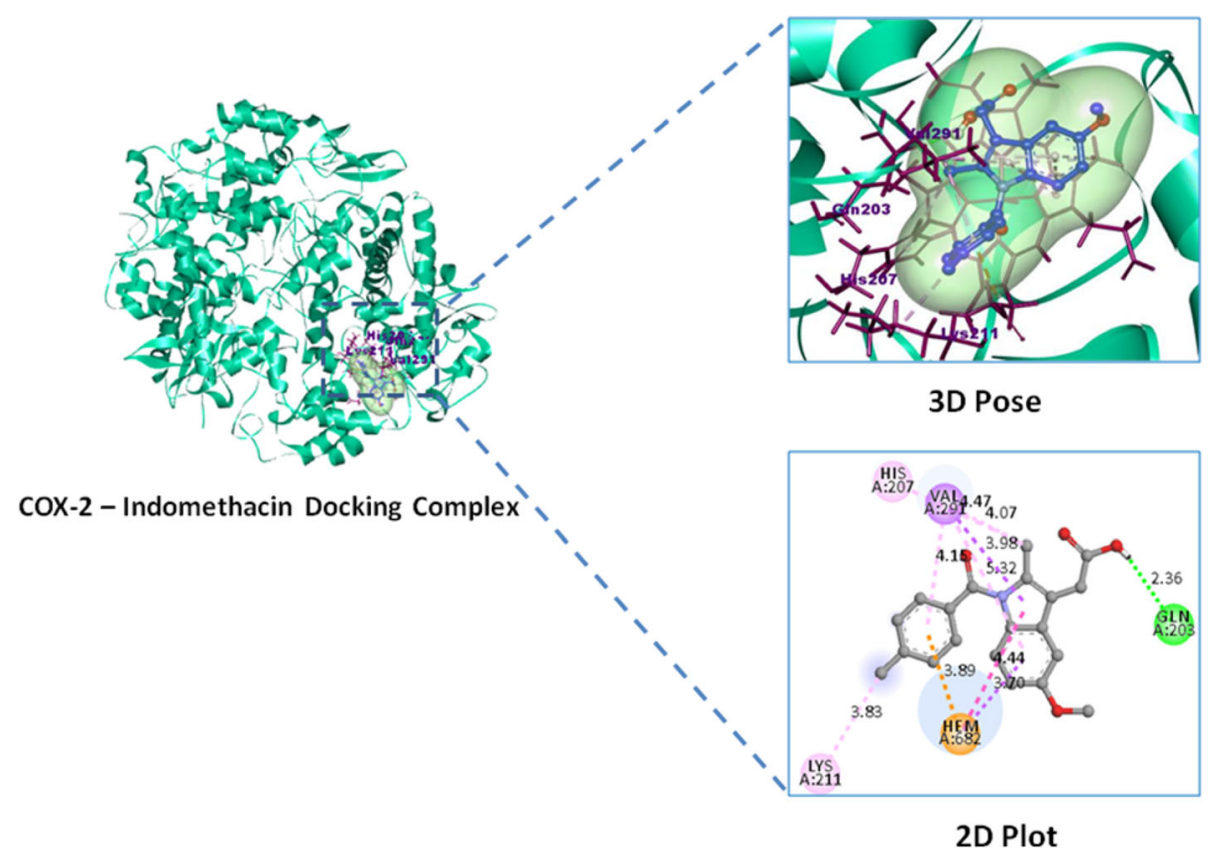

Fig. 7 Inflammatory receptor COX-2-Indomethacin (reference standard) docking complex 3D pose and their 2D interaction plot

inflammatory sites. Our study reveals that lupeol fractions of Crateva adansonii evoke promising inflammation inhibition and suggested its role in the suppression of inflammatory mediators.

The study was further extended to evaluate LF possible effects on monocyte and leukocyte migration at the inflammatory sites. This was done through assessing the effect of LF on monocyte chemoattractant protein-1 (MCP-1) and RANTES (regulated upon activation, normal $\mathrm{T}$ cell expressed and secreted). MCP-1 is a pro inflammatory cytokine responsible for the infiltration of monocytes at inflammatory sites [44]. Rise in RANTES production is closely associated with a broad range of inflammatory conditions. It acts by

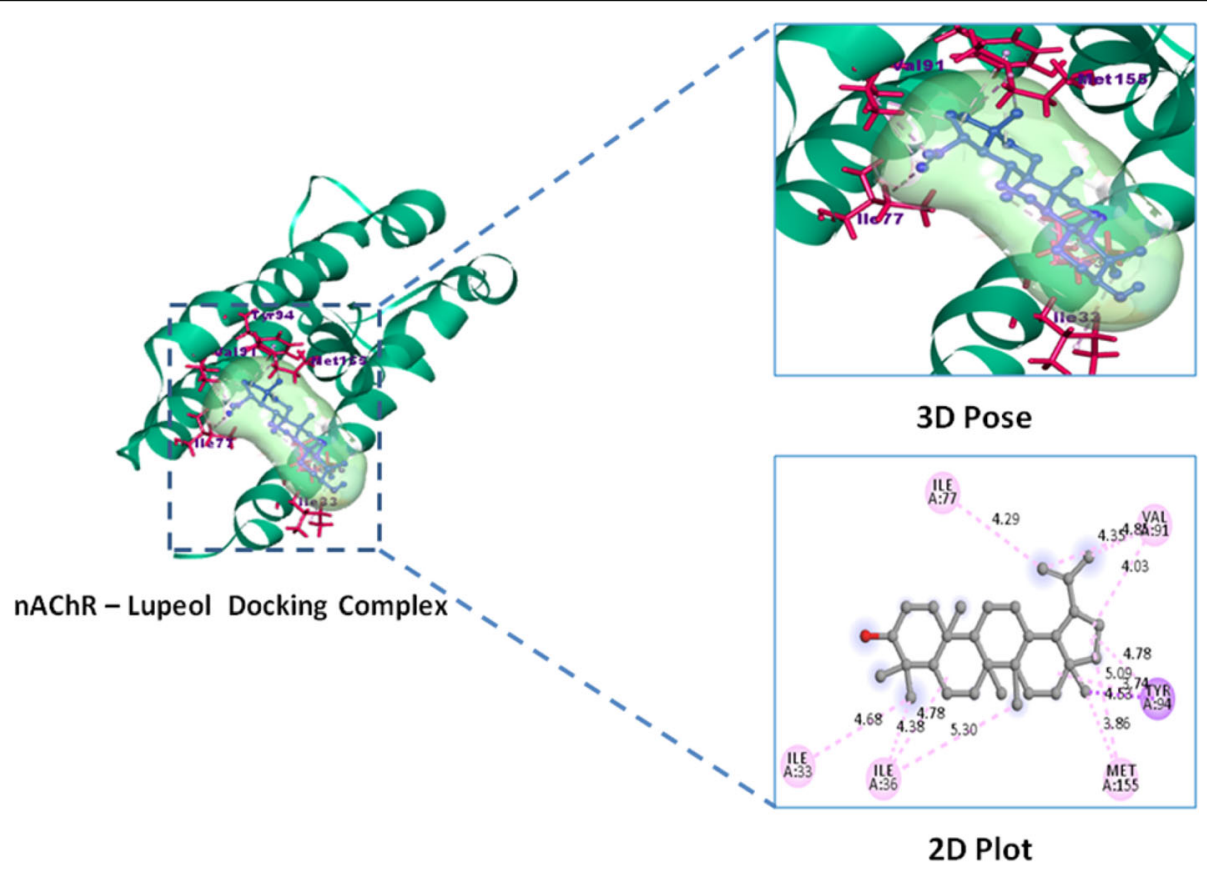

Fig. 8 Analgesic receptor nAChR-Lupeol docking complex 3D pose and their 2D interaction plot 


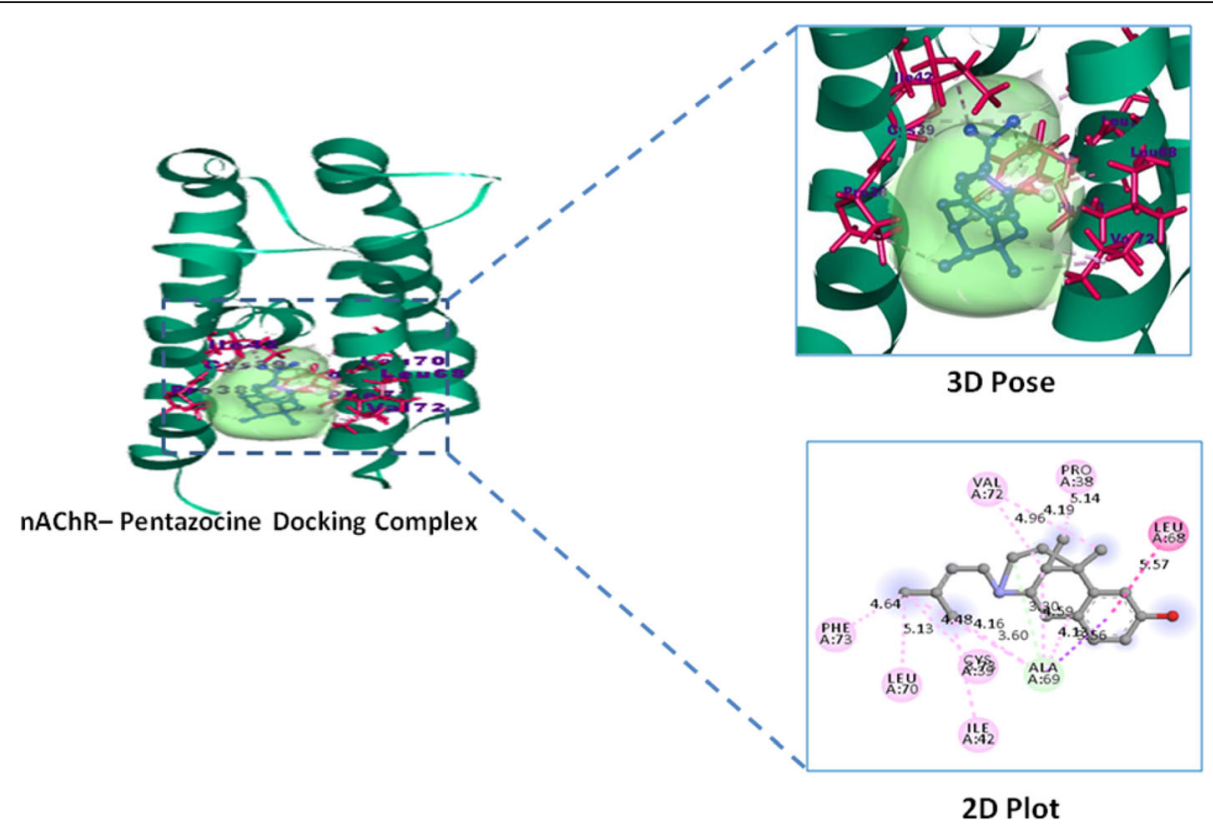

Fig. 9 Analgesic receptor nAChR-Pentazocine (reference standard) docking complex 3D pose and their 2D interaction plot

promoting leukocyte infiltration to the site of inflammation. RANTES induces activation of $\mathrm{T}$ cells [45] followed by amplified production of IL-2 and IFN- $\gamma$. In the current study, LF from Crateva adansonii alleviated carrageenan-induced RANTES production. As a result of RANTES inhibition by LF unable to activate $\mathrm{T}$ cell, this was observed through reduced IFN- $\gamma$ production. Taken altogether, LF could remarkably affect and reduces monocyte and leukocyte migration as evident from alleviated MCP-1 and RANTES production. The level of macrophage inflammatory protein (MIP) in paw edema exudates of carrageenan-treated rats was found to be significantly reduced in LF pretreated rats.

Hot plate method is widely employed to screen and evaluate analgesic drug acting central nociceptive system [46, 47], which contribute significant pain generation upon inflammation and nerve injury. It is one of the models normally used for studying central nociceptive activity [48]. Analgesic potential of any anti-nociceptive agent acting on central nociceptive system causes a prolongation of hot plate latency period [49]. Lupeol fraction of the Crateva adansonii shows equipotent analgesic activity compared with opioid standard pentazocine acting on central nociceptive system. Narcotic analgesics inhibit both peripheral and central mechanism of pain, while NSAIDs inhibit only peripheral pain [50, 51]. Therefore, Crateva adansonii leaf extracts and lupeol fractions showed both types of pain inhibition. The analgesic effect of the plants in both models suggests that they have been acting through central and peripheral mechanism [48]. Groups VI and VII animals receiving chloroform leaf extract and LF of Crateva adansonii showed remarkable analgesic activity (10.22 \pm $0.32 \mathrm{~s}$ and $11.60 \pm 0.96 \mathrm{~s}$ at $120 \mathrm{~min}$ respectively) in hot plate assay; it indicates that LF and CE of plant Crateva adansonii possess excellent equipotent CNS analgesic efficiency and when compared with standard drug pentazocine (10.76 $\pm 0.06 \mathrm{~s}$ at $120 \mathrm{~min})$.

Analgesic activity was assessed by acetic acid-induced writhing assay which is widely employed and reported valuable investigation method for assessing central and peripheral antinociceptive activity of pharmacological important substances and performed as a chemical pain model [52]. Prostaglandin level of peritoneal exudates of mice is elevated at $30 \mathrm{~min}$ after the injection of acetic acid $[53,54]$. The degree of writhing obtained in the assay is well correlated with the sensitization of pain receptors followed by the elevated level of prostaglandin. Writhing assay results revealed that group VI animals receiving $400 \mathrm{mg}$ CE (61.26\%) and group VII animals receiving LF (69.05\%) possess equipotent analgesic efficiency when compared with the standard drug pentazocine (70.05\%).

Previously reported in silico studies of COX-2 with natural compounds (epiloganin, curcumin, lupeol) and celecoxib, indomethacin reveals that compounds from natural origin have anti-inflammatory therapeutic value that possess highest binding affinity with least docking scores than commercial reference standard drugs [55, 56]. Similarly, our present study has shown that lupeol phytocompounds isolated from Crateva adansonii leaf extract shows the higher binding affinity toward COX-2 
enzyme than commercial available NSAIDs drugs including COX-2 selective inhibitors [57].

\section{Conclusion}

The present study results well explains and support the folkloric usage of Crateva adansonii plant leaf in different inflammatory and nociceptive disease conditions in India. Acute toxicity screening reveals that no lethality was noticed to experimental rats by administration of Crateva adansonii leaf extract up to $2 \mathrm{~g} / \mathrm{kg}$. Further, the study demonstrates lupeol containing LF of the plant possess equipotent analgesic and anti-inflammatory activity compared with the standard drugs such as pentazocine and indomethacin. LF and leaf extract from Crateva adansonii shown to inhibit prostaglandin, inflammatory enzyme myeloperoxidase, and inflammatory cytokines release associated with pain and inflammatory pathways. Finally, LF from Crateva adansonii has proven its remarkable analgesic effect in both hot plate and acetic acid-induced writhing mice in vivo models. The present study provides in vivo pharmacological evidences for analgesic and anti-inflammatory potential of lupeol isolated from Indian traditional plant Crateva adansonii act as cheapest sources for multi-target agent with immense analgesic and anti-inflammatory potentials.

\section{Abbreviations}

CE: Chloroform extract; CMC: Carboxy methyl cellulose; ME: Methanolic extract; LF: Lupeol fraction; LL: Interleukin; IFN- $\gamma$ : Interferon gamma; nAChR: Nicotinic acetylcholine receptor; COX-2: Cycloxygenase-2; MCP1: Monocyte chemoattractant protein-1; RANTES: Regulated on activation, normal T cell expressed and secreted; MIP: Macrophage inflammatory protein; INDO: Indomethacin; MPO: Myeloperoxidase; PGE2: Prostaglandin $E_{2}$

\section{Acknowledgements}

The authors express sincere gratitude to Department of Biotechnology, Sona College of Arts and Science, Salem for their technical support.

\section{Authors' contributions}

TR and SA formulated idea and collected materials. TR and SA performed the in vivo study. GS and SA made data analysis and validation. TR performed in silico analysis and wrote the initial and final form of manuscript. SA and GS reviewed the final form of manuscript. All authors read and approved the final manuscript.

\section{Funding}

The authors declare no funding for this research.

\section{Availability of data and materials}

The datasets used and analyzed during the current study available from the corresponding author on reasonable request.

\section{Declarations}

\section{Ethics approval and consent to participate}

Ethical approval for in vivo animal study obtained from Nandha College of Pharmacy, Erode, Tamil Nadu, India. IAEC approval no 688/PO/Re/S/02/ CPCSEA.

\section{Consent for publication}

Not applicable.

\section{Competing interests}

The authors declare that they have no competing interest.

\begin{abstract}
Author details
'Department of Biotechnology, Sona College of Arts and Science, Salem, Tamil Nadu 636 005, India. ${ }^{2}$ Department of Biochemistry, Rajah Serfoji Government College (Autonomous), Thanjavur, Tamil Nadu 613 005, India. ${ }^{3}$ Department of Biotechnology, Yeungnam University, Gyeongsan, South Korea.
\end{abstract}

Received: 16 February 2021 Accepted: 14 April 2021

Published online: 04 May 2021

References

1. Medzhitov R (2010) Inflammation 2010: new adventures of an old flame. Cell 140(6):771-776. https://doi.org/10.1016/j.cell.2010.03.006

2. Ferrero-Miliani L, Nielsen OH, Andersen PS, Girardin SE (2007) Chronic inflammation: Importance of NOD2 and NALP3 in interleukin-1 $\beta$ generation. Clin Exp Immunol 147(0):227-235. https://doi.org/10.1111/j.1365-2249.2006. 03261.x

3. Nathan C, Ding A (2010) Nonresolving inflammation. Cell 140(6):871-882. https://doi.org/10.1016/j.cell.2010.02.029

4. Vignali DAA, Kuchroo VK (2012) IL-12 family cytokines: immunological playmakers. Nat Immunol 13(8):722-728. https://doi.org/10.1038/ni.2366

5. Monaco C, Andreakos E, Kiriakidis S, Mauri C, Bicknell C, Foxwell B, Cheshire N, Paleolog E, Feldmann M (2004) Canonical pathway of nuclear factor KB activation selectively regulates proinflammatory and prothrombotic responses in human atherosclerosis. Proc Natl Acad Sci U S A 101(15):56345639. https://doi.org/10.1073/pnas.0401060101

6. Venuraju SM, Yerramasu A, Corder R, Lahiri A (2010) Osteoprotegerin as a predictor of coronary artery disease and cardiovascular mortality and morbidity. J Am Coll Cardiol 55(19):2049-2061. https://doi.org/10.1016/j.ja cc.2010.03.013

7. Tasneem S, Liu B, Li B, Choudhary MI, Wang W (2019) Molecular pharmacology of inflammation: medicinal plants as anti-inflammatory agents. Pharmacol Res 139:126-140. https://doi.org/10.1016/j.phrs.2018.11. 001

8. Ribeiro VP, Arruda C, El-Salam MA, Bastos JK (2018) Brazilian medicinal plants with corroborated anti-inflammatory activities: a review. Pharm Biol 56(1):253-268. https://doi.org/10.1080/13880209.2018.1454480

9. Oguntibeju OO (2018) Medicinal plants with anti-inflammatory activities from selected countries and regions of africa. J Inflamm Res 11:307-317. https://doi.org/10.2147/JIR.S167789

10. Yamaki J, Venkata KCN, Mandal A, Bhattacharyya P, Bishayee A (2016) Health-promoting and disease-preventive potential of Trianthema portulacastrum Linn. (Gadabani) - an Indian medicinal and dietary plant. J Integr Med 14(2):84-99. https://doi.org/10.1016/S2095-4964(16)60247-9

11. Maione F, Russo R, Khan H, Mascolo N (2016) Medicinal plants with antiinflammatory activities. Nat Prod Res 30(12):1343-1352. https://doi.org/10.1 080/14786419.2015.1062761

12. Gitte TA, Kare MA, Deshmukh AM (2012) Ethno- medicinal studies on barks of some medicinal plants in Marathwada (M.S.). Rec Res Sci Tech 4:8-10

13. Abdullahi A, Hamzah R, Jigam A, Yahya A, Kabiru A, Muhammad H, Sakpe S, Adefolalu FS, Isah MC, Kolo MZ (2012) Inhibitory activity of xanthine oxidase by fractions Crateva adansonii. J Acute Dis 1(2):126-129. https://doi.org/10.1 016/s2221-6189(13)60029-3

14. Thirumalaisamy R, Ammashi S, Muthusamy G (2018) Screening of antiinflammatory phytocompounds from Crateva adansonii leaf extracts and its validation by in silico modeling. J Genet Eng Biotechnol 16(2):711-719. https://doi.org/10.1016/j.jgeb.2018.03.004

15. Thirumalaisamy $R$, Ameen F, Subramanian A, Selvankumar T, Alwakeel SS, Govarthanan M (2020) In-vitro and in-silico anti-inflammatory activity of Lupeol isolated from Crateva adansonii and its hidden molecular mechanism. Int J Pept Res Ther 26(4):2179-2189. https://doi.org/10.1007/s1 0989-019-10006-5

16. OECD (2002) Test no. 423: acute oral toxicity - acute toxic class method. Oecd Guidel Test Chem:1-14. https://doi.org/10.1787/9789264071001-en

17. Winter CA, Risley EA, Nuss GW (1962) Carrageenin-induced edema in hind paw. Exp Biol Med 3:544-547

18. Subash A, Veeraraghavan G, Sali VK, Bhardwaj M, Vasanthi HR (2016) Attenuation of inflammation by marine algae Turbinaria ornata in cotton 
pellet induced granuloma mediated by fucoidan like sulphated polysaccharide. Carbohydr Polym 151:1261-1268. https://doi.org/10.1016/j. carbpol.2016.06.077

19. Virella G (1993) Introduction to medical immunology, vol 58. https://doi. org/10.1016/0165-2427(87)90040-7

20. WINTER CA, PORTER CC (1957) Effect of alterations in side chain upon antiinflammatory and liver glycogen activities of hydrocortisone esters. J Am Pharm Assoc Am Pharm Assoc (Baltim) 46(9):515-519. https:/doi.org/10.1002/jps.3030460902

21. Calva-Candelaria N, Meléndez-Camargo ME, Montellano-Rosales H, EstradaPérez AR, Rosales-Hernández MC, Fragoso-Vázquez MJ, Martínez-Archundia M, Correa-Basurto J, Márquez-Flores YK (2018) Oenothera rosea L’Hér. ex Ait attenuates acute colonic inflammation in TNBS-induced colitis model in rats: in vivo and in silico myeloperoxidase role. Biomed Pharmacother 108 852-864. https://doi.org/10.1016/j.biopha.2018.09.081

22. Langford DJ, Mogil JS (2008) Pain testing in the laboratory mouse, 2nd edn. Elsevier Inc. https://doi.org/10.1016/B978-012373898-1.50027-9

23. Trott O, Olson AJ (2009) AutoDock Vina: improving the speed and accuracy of docking with a new scoring function, efficient optimization, and multithreading. J Comput Chem 31:NA. https://doi.org/10.1002/jcc.21334

24. Berman HM, Bluhm WF, Philip E, Marvin J, Weissig H, John D (2002) The Protein Data Bank research papers. Acta Cryst D58:899-907

25. Weininger D (1988) SMILES, a chemical language and information system: 1 : Introduction to methodology and encoding rules. J Chem Inf Comput Sci 28(1):31-36. https://doi.org/10.1021/ci00057a005

26. Neergheen-Bhujun VS (2013) Underestimating the toxicological challenges associated with the use of herbal medicinal products in developing countries. Biomed Res Int 2013:1-9. https://doi.org/10.1155/2013/804086

27. Jothy SL, Zakaria Z, Chen Y, Lau YL, Latha LY, Sasidharan S (2011) Acute oral toxicity of methanolic seed extract of Cassia fistula in mice. Molecules 16(6): 5268-5282. https://doi.org/10.3390/molecules16065268

28. Bradley PP, Priebat DA, Christensen RD, Rothstein G (1982) Measurement of cutaneous inflammation: estimation of neutrophil content with an enzyme marker. J Invest Dermatol 78(3):206-209. https://doi.org/10.1111/1523-1747. ep12506462

29. Brooks RR, Carpenter JF, Jones SM, Ziegler TC, Pong SF (1991) Canine carrageenin-Induced acute paw inflammation model and its response to nonsteroidal antiinflammatory drugs. J Pharmacol Methods 25(4):275-283. https://doi.org/10.1016/0160-5402(91)90027-3

30. Lopes AH, Silva RL, Fonseca MD, Gomes FI, Maganin AG, Ribeiro LS, Marques LMM, Cunha FQ, Alves-Filho JC, Zamboni DS, Lopes NP, Franklin BS, Gombault A, Ramalho FS, Quesniaux VFJ, Couillin I, Ryffel B, Cunha TM (2020) Molecular basis of carrageenan-induced cytokines production in macrophages. Cell Commun Signal 18(1):1-17. https:/doi.org/10.1186/s12964-020-00621-x

31. El-Shenawy SM, Abdel-Salam OME, Baiuomy AR, El-Batran S, Arbid MS (2002) Studies on the anti-inflammatory and anti-nociceptive effects of melatonin in the rat. Pharmacol Res 46(3):235-243. https://doi.org/10.1016/S1043-6618(02)00094-4

32. Hua XY, Chen P, Fox A, Myers RR (1996) Involvement of cytokines in lipopolysaccharide-induced facilitation of CGRP release from capsaicinsensitive nerves in the trachea: studies with interleukin-1 $\beta$ and tumor necrosis factor-a. J Neurosci 16(15):4742-4748. https://doi.org/10.1523/ jneurosci.16-15-04742.1996

33. Di Rosa M, Giroud JP, Willoughby DA (1971) Studies of the mediators of the acute inflammatory response induced in rats in different sites by carrageenan and turpentine. J Pathol 104(1):15-29. https://doi.org/10.1002/path.1711040103

34. Sánchez-Burgos JA, Ramírez-Mares MV, Gallegos-Infante JA, González-Laredo RF, Moreno-Jiménez MR, Cháirez-Ramírez MH, Medina-Torres L, RochaGuzmán NE (2015) Isolation of lupeol from white oak leaves and its antiinflammatory activity. Ind Crops Prod 77:827-832. https://doi.org/10.1016/j. indcrop.2015.09.056

35. Janaki S, Vijayasekaran V, Viswanathan S, Balakrishna K (1999) Antiinflammatory activity of Aglaia roxburghiana var. beddomei extract and triterpenes roxburghiadiol A and B. J Ethnopharmacol 67(1):45-51. https:// doi.org/10.1016/S0378-8741(99)00063-X

36. Huang M-T, Ghai G, Ho C-T (2004) Inflammatory process and molecular targets for antiinflammatory nutraceuticals. Compr Rev Food Sci Food Saf 3(4):127-139. https://doi.org/10.1111/j.1541-4337.2004.tb00063.x

37. Frolov A, Yang L, Dong H, Hammock BD, Crofford LJ (2013) Antiinflammatory properties of prostaglandin E2: deletion of microsomal prostaglandin E synthase-1 exacerbates non-immune inflammatory arthritis in mice. Prostaglandins Leukot Essent Fat Acids 89(5):351-358. https://doi. org/10.1016/j.plefa.2013.08.003
38. Monastero RN, Pentyala S (2017) Cytokines as biomarkers and their respective clinical cutoff levels. Int J Inflam 2017:1-11. https://doi.org/10.11 55/2017/4309485

39. Dzoyem JP, McGaw LJ, Kuete V, Bakowsky U (2017) Anti-inflammatory and anti-nociceptive activities of African Medicinal spices and vegetables. Elsevier Inc. https://doi.org/10.1016/B978-0-12-809286-6.00009-1

40. Deraedt R, Jouquey S, Delevallée F, Flahaut M (1980) Release of prostaglandins $\mathrm{E}$ and $\mathrm{F}$ in an algogenic reaction and its inhibition. Eur J Pharmacol 61(1):17-24. https://doi.org/10.1016/0014-2999(80)90377-5

41. Silva RO, Sousa FBM, Damasceno SRB, Carvalho NS, Silva VG, Oliveira FRMA, Sousa DP, Aragão KS, Barbosa ALR, Freitas RM, Medeiros JVR (2014) Phytol, a diterpene alcohol, inhibits the inflammatory response by reducing cytokine production and oxidative stress. Fundam Clin Pharmacol 28(4):455-464. https://doi.org/10.1111/fcp.12049

42. Ezzat SM, Ezzat MI, Okba MM, Menze ET, Abdel-Naim AB (2018) The hidden mechanism beyond ginger (Zingiber officinale Rosc.) potent in vivo and in vitro anti-inflammatory activity. J Ethnopharmacol 214:113-123. https:// doi.org/10.1016/j.jep.2017.12.019

43. Ko JKS, Sham NF, Guo X, Cho CH (2001) Beneficial intervention of experimental colitis by passive cigarette smoking through the modulation of cytokines in rats. J Investig Med 49(1):21-29. https://doi.org/10.2310/6650.2001.34087

44. Rollins BJ (1996) Monocyte chemoattractant protein 1: a potential regulator of monocyte recruitment in inflammatory disease. Mol Med Today 2(5):198204. https://doi.org/10.1016/1357-4310(96)88772-7

45. Appay V, Rowland-Jones SL (2001) RANTES: a versatile and controversial chemokine. Trends Immunol 22(2):83-87. https:/doi.org/10.1016/S1471-4906(00)01812-3

46. De Souza MM, Pereira MA, Ardenghi JV, Mora TC, Bresciani LF, Yunes RA et al (2009) Filicene obtained from Adiantum cuneatum interacts with the cholinergic, dopaminergic, glutamatergic, GABAergic, and tachykinergic systems to exert antinociceptive effect in mice. Pharmacol Biochem Behav 93(1):40-46. https://doi.org/10.1016/j.pbb.2009.04.004

47. Hernier AM, Froger-Colléaux C, Castagné V (2016) CNS safety pharmacology: a focus on cognitive functions. J Pharmacol Toxicol Methods 81:286-294. https://doi.org/10.1016/j.vascn.2016.04.002

48. Sabina EP, Rasool MK, Mathew L (2009) In vivo and in vitro immunomodulatory effects of Indian ayurvedic herbal formulation triphala on experimental induced inflammation. Pharmacologyonline 2:840-849

49. Ibironke GF, Ajiboye KI (2007) Studies on the anti-inflammatory and analgesic properties of Chenopodium ambrosioides leaf extract in rats. Int J Pharmacol 3(1):111-115. https://doi.org/10.3923/ijp.2007.111.115

50. Sajid M, Khan MR, Shah SA, Majid M, Ismail H, Maryam S, Batool R, Younis T (2017) Investigations on anti-inflammatory and analgesic activities of Alnus nitida Spach (Endl). stem bark in Sprague Dawley rats. J Ethnopharmacol 198:407-416. https://doi.org/10.1016/j.jep.2017.01.041

51. Pal S, Sen T, Chaudhuri AKN (1999) Neuropsychopharmacological profile of the methanolic fraction of Bryophyllum pinnatum leaf extract. J Pharm Pharmacol 51(3):313-318. https://doi.org/10.1211/0022357991772312

52. Abdollahi M, Karimpour H, Monsef-Esfehani HR (2003) Antinociceptive effects of Teucrium polium L. total extract and essential oil in mouse writhing test. Pharmacol Res 48(1):31-35. https://doi.org/10.1016/S1043-6618(03)00059-8

53. Ye Y, Guo Y, Luo YT (2012) Anti-inflammatory and analgesic activities of a novel biflavonoid from shells of camellia oleifera. Int J Mol Sci 13(12):1240112411. https://doi.org/10.3390/ijms131012401

54. Maiti K, Mukherjee K, Murugan V, Saha BP, Mukherjee PK (2010) Enhancing bioavailability and hepatoprotective activity of andrographolide from Andrographis paniculata, a well-known medicinal food, through its herbosome. J Sci Food Agric 90(1):43-51. https://doi.org/10.1002/jsfa.3777

55. Aziz MA, Mehedi M, Akter MI, Sajon SR, Mazumder K, Rana MS (2020) Correction to: in vivo and in silico evaluation of analgesic activity of Lippia alba. Clin Phytoscience 6(1):1-9. https://doi.org/10.1186/s40816-019-0148-5

56. Sohilait MR, Pranowo HD, Haryadi W (2017) Molecular docking analysis of curcumin analogues with COX-2. Bioinformation 13(11):356-359. https://doi. org/10.6026/97320630013356

57. Thirumalaisamy R, Subramanian A, Shanmugam G (2018) In silico Validation of Phytocompounds from Crateva adansonii against Multiple Targets of Inflammation. Int J Adv Interdis Res 6(1):6-16

\section{Publisher's Note}

Springer Nature remains neutral with regard to jurisdictional claims in published maps and institutional affiliations. 